\title{
Pancreatitis and duodenal obstruction due to periampullary carcinoma associated with familial polyposis coli
}

\author{
D. N. Clarke \\ M.B., Ch.B., M.R.C.P. \\ J. N. NORMAN \\ Ph.D., M.D., F.R.C.S.
}

\author{
J. A. R. SMITH \\ M.B., Ch.B., F.R.C.S. \\ P. W. BRUNT \\ M.D., F.R.C.P.
}

Department of Medicine and Surgery, University of Aberdeen

\begin{abstract}
Summary
Duodenal lesions are being reported in cases with familial polyposis of the colon. A case is described presenting with duodenal obstruction and pancreatitis complicating a peri-ampullary carcinoma in a patient with familial polyposis (adenomatosis of the colon and rectum). Upper gastrointestinal lesions notably in the duodenum include duodenal polyps and carcinoma and peri-ampullary malignancy. It is suggested that endoscopy and hypotonic duodenography be considered in patients with adenomatosis of the colon and rectum presenting with non-colonic alimentary symptoms.
\end{abstract}

\section{Introduction}

Hereditary adenomatosis of the colon and rectum (ACR) - also known as familial polyposis of the colon (FPC) may exist as a distinct entity, or in association with soft tissue tumours, epidermoid cysts and osteomata; the latter association is known as Gardner's syndrome. There have been increasing reports in the literature of an association between Gardner's syndrome and the development of duodenal, peri-ampullary and pancreatic carcinomas. The present case reported is unique in that the patient presented with duodenal obstruction and pancreatitis secondary to peri-ampullary carcinoma associated with ACR as distinct from Gardner's syndrome.

The patient, a 31-year-old male was admitted with symptoms of anaemia, right hypochondrial pain and melaena. Positive features on examination were a tachycardia and anaemia. Investigation included: $\mathrm{Hb} 5.0 \mathrm{~g} / \mathrm{dl}$, reticulocyte count $6 \%$ and urea 2.96 i.u./l. He was transfused with 4 pints of blood and despite a negative barium meal he was discharged with a diagnosis of a suspected peptic ulcer.

He remained well until 1 year later when he com-

Correspondence: Dr P. W. Brunt, F.R.C.P., Gastroenterology Research Unit, Royal Infirmary, Foresterhill, Aberdeen AB9 2ZB. plained of weakness, bright red rectal bleeding and diarrhoea. Family history disclosed that his mother had died at the age of 41 years from large bowel cancer and that three sibs had also undergone a pan-procto colectomy. Two sibs remained alive and well. Sigmoidoscopy showed pus, blood and masses of polypi. Barium enema confirmed the presence of diffuse polyposis and he underwent a pan-proctocolectomy. The colon on pathological examination was found carpeted with adenomatous polyps from the caecum to the rectum.

At the age of 42 years he was admitted with a three-week history of epigastric pain, vomiting and melaena suggestive of a peptic ulcer. His pulse was $80 / \mathrm{min}$, BP $130 / 80 \mathrm{mmHg}$ and he had slight epigastric guarding. No soft tissue or bony tumours were found. Investigation including urea and electrolytes, serum proteins, chest X-ray, barium meal and follow through were all normal. Gastrointestinal endoscopy including careful visualization of the first part of the duodenum revealed no abnormality or bleeding site. His $\mathrm{Hb}$ was $6 \cdot 1 \mathrm{~g} / \mathrm{dl}$ and he was transfused with 9 pints of blood. Later he was troubled with persistent vomiting but this resolved on metoclopramide. Shortly after discharge from hospital he was readmitted with colicky epigastric pain and vomiting. He was noted to be dehydrated and a succussion splash was heard over the stomach. The serum amylase was elevated to 9900 i.u./l and a gastrografin meal showed a normal duodenal loop but slight elevation of the pyloric antrum. He was treated conservatively for acute pancreatitis. On cessation of therapy he again developed epigastric pain and vomiting. A repeat barium meal now showed a stricture in the third part of the duodenum thought to be carcinomatous and widening of the duodenal loop with mucosal irregularity consistent with acute pancreatitis.

Laparotomy 2 months after admission revealed acute pancreatitis with puckering of the third part 
of the duodenum owing to the presence of an intrinsic neoplasm. Metastases were found in the right lobe of the liver and a palliative gastroenterostomy was performed. He made a good recovery but one month later his mental state altered and a left deep frontal lesion was confirmed by a brain scan. A few months later he became hyponatraemic, developed obstructive jaundice and died 7 months after admission.

Post-mortem examination revealed a fungating growth $8 \mathrm{~cm}$ from the pylorus occluding the lumen of the duodenum and blocking the distended bile duct. The liver was riddled with metastatic deposits and the brain contained a $5-\mathrm{cm}$ metastasis in the left frontal region. Histological examination of the primary growth showed a papillary structured tumour covered by tall columnar epithelium. The appearances were those of an ampullary adeno-carcinoma. No duodenal polyps were found.

\section{Discussion}

Menzel in 1721 first reported intestinal polyposis but the condition which we now know as hereditary adenomatosis of the colon and rectum (ACR) was first described by Charlelaigne in 1859. Cripps in 1882 first alluded to its hereditary nature by describing the condition in two sibs but it was only in 1927 that Coccayne postulated that the mode of transmission was by dominant Mendelian inheritance. The association of ACR with colonic carcinoma was first mentioned by Handford in 1890 . Today many more extra-colonic associations have been described with ACR, the best known being the occurrence of multiple epidermoid cysts, soft tissue tumours of the skin and osteomata of the skull and mandible, given the eponym 'Gardner's syndrome' after Gardner and Richard's publication in 1953.

Various reports have been made in the literature of duodenal polyps, duodenal carcinoma, and peri-ampullary malignancy in association with Gardner's syndrome and ACR (MacDonald et al., 1967; McFarland, Scheetz and Knisley, 1968; Parks, Bussey and Lockhart-Mummery, 1970; Capps, Lewis and Gazzaniga, 1968; Muir, Bell and Barlow, 1967; Melmed and Bouchier, 1972; Mir-Madjlessi et al., 1973. The pathological involvement can be classified into three main groups; (a) the occurrence of duodenal polyps, (b) duodenal carcinoma which may be multicentric and (c) peri-ampullary carcinoma. The precise differentiation of the latter two groups may be impossible on both clinical and pathological grounds. In Gardner's syndrome there have been two reports of duodenal carcinoma one of which, like the case here described, presented with duodenal obstruction (Parks et al., 1970; Muir et al., 1967). A further seven cases with peri-ampullary malignancy have been recorded. Three more cases have been described in which Gardner's syndrome was associated with duodenal polyps. With ACR without other extra-colonic manifestations there have been three reports of peri-ampullary malignancy including the case presented here which was the only one to have pancreatitis and duodenal obstruction as a feature. Pancreatitis in this instance would appear to have been the result of obstruction of the ampulla of Vater itself by tumour.

From this case and a review of the literature it is apparent that the diagnosis of duodenal polyps, duodenal carcinoma and an early peri-ampullary malignancy is difficult and may be missed on a routine barium meal and follow-through. In a recent report from Japan, eleven cases of ACR were followed-up for 11 years with particular regard to the upper gastrointestinal tract; in their series nine cases had polyps and/or carcinoma of the stomach and duodenum (Osato et al., 1975). In five cases, polyps were found in the stomach and duodenum including one case with multicentric gastric carcinoma and in two cases the polyps were in the duodenum only and in one case the stomach only.

In summary, upper gastrointestinal lesions are being increasingly recognized and certainly ought to be kept in mind when patients with ACR develop any unusual symptoms including jaundice, cholangitis, nausea and vomiting and non-specific abdominal pain. Hypotonic duodenography and endoscopy are essential procedures to help establish an early diagnosis and if negative ought to be repeated if symptoms continue. Routine follow-up of patients with ACR even after pan-procto-colectomy and in certain cases gastroduodenoscopy may be desirable.

\section{References}

CaPps JR, W.F., Lewis, M.I. \& Gazzaniga, D.A. (1968) Carcinoma of the colon, ampullar of Vater and urinary bladder associated with familial multiple polyposis: a case report. Diseases of the Colon and Rectum, 11, 298.

Charlelaigne, A. (1859) Des polypes du rectum. Medical Faculty of Paris, 3.

Coccayne, E.A. (1927) Heredity in relation to cancer. Cancer Review, 2, 337.

CRIPPS, W.H. (1882) Two cases of disseminated polypus of the rectum. Transactions of the Pathological Society London, 33, 165.

GARDNER, E.J. \& RiChARDS, R.C. (1953) Multiple cutaneous and subcutaneous lesions occurring simultaneously with hereditary polyposis and osteomatosis. American Journal of Human Genetics, 5, 139.

HANDFORD, H. (1890) Disseminated polypi of the large intestine becoming malignant; strictures (malignant adenoma) of the rectum and of the splenic flexure of the colon; secondary growths in the liver. Transactions of the Pathological Society London, 41, 133.

MacDonald, J.M., Davis, W.C., Crago, H.R. \& Berk, A.D. (1967) Gardner's syndrome and periampullar malignancy. American Journal of Surgery, 113, 425. 
McFarland JR, P.H., Scheetz, W.L. \& KNISLey, R.E. (1968) Gardner's syndrome: Report of two families. Journal of Oral Surgery, 26, 632.

Melmed, R.N. \& BouchieR, I.A.D. (1972) Duodenal involvement in Gardner's syndrome. Gut, 13, 524.

Menzel, D. (1721) Quoted by HewitT and Howard (1915).

Mir-Madjlessi, S.H., Farmer, R.G., HaWK, W.A. \& TuRnBUll JR, R.B. (1973) Adenocarcinoma of the ampulla of Vater associated with familial polyposis coli. Report of a case. Diseases of the Colon and Rectum. 6, 542.
Muir, E.G., Bell, A.J.Y. \& Barlow, K.A. (1967) Multiple primary carcinomata of the colon, duodenum and larynx associated with kerato-acanthomata of the face. British Journal of Surgery, 54, 191.

Osato, K., ItOH, H., IKedA, S., Nishimura, M., YaO, T., IIDA, M. \& WATANABE, H. (1975) Upper gastro-intestinal lesions in familial polyposis of the colon. Japanese Journal of Gastroenterology, 72, 141.

Parks, T.G., Bussey, H.J.R. \& LoCKhart-Mummery, H.E. (1970) Familial polyposis coli associated with extracolonic abnormalities. Gut, 11, 323. 